\title{
Hermandades castellanas y centralización monárquica (1325-1476): algunas consideraciones"
}

\author{
José María Sánchez Benito ${ }^{1}$ \\ Universidad Autónoma de Madrid \\ josemaria.sanchez@uam.es
}

\begin{abstract}
RESUMEN: Este artículo pretende profundizar en el análisis de los complejos cambios que presenta la evolución de las hermandades castellanas entre 1325 y 1476. Lo haremos conjugando la diversidad de las muchas iniciativas de carácter concejil que fueron surgiendo en distintos rincones del reino y la tendencia a la unidad y el control regio que se inicia tempranamente y cristaliza en tiempos de Isabel y Fernando. Por lo tanto, destacaremos el papel de los reyes en este proceso y la forma en que se abrió camino la idea de una institución entendida como instrumento para el ejercicio del poder monárquico.
\end{abstract}

Palabras ClaVE: hermandad; concejos; Monarquía; guerra; Castilla.

* Este trabajo forma parte del proyecto de investigación «Ciudad y nobleza en el tránsito a la Modernidad: autoritarismo regio, pactismo y conflictividad política. Castilla, de Isabel I a las Comunidades», ref. HAR2017-83542-P, financiado por el Ministerio de Ciencia, Innovación y Universidades/AEI/FEDER 2018-2021.

Abreviaturas de archivos: Archivo de la Catedral de Toledo, Toledo (AC T); Archivo Histórico de la Nobleza, Toledo (AHN-N); Archivo Municipal de Burgos, Burgos (AM Bu); Archivo Municipal de Cuenca, Cuenca (AM Cu); Archivo Municipal de León, León (AM Le); Archivo Municipal de Murcia, Murcia (AM Mu); Archivo Municipal de Talavera, Talavera de la Reina, Toledo (AM Ta); Archivo Municipal de Toledo, Toledo (AM T); Archivo de la Diputación Provincial de Toledo, Toledo (ADP T); Biblioteca Nacional, Madrid (BN); Real Academia de la Historia, Madrid (RAH).

1 ORCID iD: https://orcid.org/0000-0001-8817-1100 


\section{Castilian brotherhoods and monarchical centralization (1325-1476): a few considerations}

ABSTRACT: This article seeks to analyse in greater depth the complex changes in the evolution of the Castilian brotherhoods between 1325 and 1476. To do so, we have juxtaposed the diverse council initiatives that were emerging in various corners of the kingdom, and the tendency to unity and royal control that began at an early stage and crystallized during the reign of Isabella and Ferdinand. We will therefore highlight the role which the monarchs played in the process, and show how they paved the way for an institution that was seen as an instrument for the exercise of royal power.

KEY WORDS: brotherhood; councils; Monarchy; war; Castile.

CÓMO CITAR ESTE ARTíCULO / CITATION: Sánchez Benito, José María, «Hermandades castellanas y centralización monárquica (1325-1476): algunas consideraciones», Hispania, 81/268 (Madrid, 2021): 455-482. https://doi.org/10.3989/hispania.2021.013.

Muchas veces se ha hablado de las hermandades castellanas y se ha insistido en el papel que desempeñan en la centralización regia, sobre todo pensando en la que se desarrolló durante el reinado de los Reyes Católicos. Siendo esto así, el objetivo principal de este artículo es muy claro, se trata de observar el desarrollo del movimiento hermandino en Castilla entre 1325 y 1476 , prestando atención a las dos vertientes que presenta. Tales vertientes son las siguientes: de un lado, las iniciativas de carácter local, directamente vinculadas a los concejos; y, de otro, las propuestas regias encaminadas a utilizar el concepto hermandad al modo de un instrumento que facilitase el ejercicio del poder monárquico y diese respuesta a retos de gran importancia que obstaculizaban su expansión. De esta suerte, pretendemos comprobar la dialéctica que hay entre ambas y el modo en que cada una de ellas se formula, así como el alcance, mayor o menor, que tuvieron en los diversos contextos políticos. Sin duda, a lo largo de la cronología que nos hemos fijado, encontraremos realidades institucionales bastante distintas, a medida que ambas vertientes evolucionan, pero, como veremos, las hermandades propiamente concejiles nunca podrán ir más allá de lo meramente coyuntural ${ }^{2}$. Finalmente, culminaremos nuestro recorrido abundando en las continuidades que se pueden observar de manera evidente en los proyectos hermandinos que se desarrollaron tras la subida al trono de la reina Isabel, cuya mitificación es de sobra conocida.

\footnotetext{
${ }^{2}$ No tomaré en consideración en este artículo los muchos acuerdos de vecindad que, muchas veces, bajo el nombre «hermandad» regulan cuestiones de pastos, linderos, etc., aunque a la postre, su importancia fue mayor y más duradera que la de otras hermandades.
} 


\section{LA HERMANDAD COMO INSTRUMENTO DEL TRONO: LOS DIFÍCILES COMIENZOS DE UNA IDEA}

El presente artículo tiene un punto de partida perfectamente definido. En 1325, tras llegar a la mayoría de edad, Alfonso XI puso punto final, en las Cortes, a la etapa acaso más brillante y espectacular de las hermandades castellanas. De hecho, en los años inmediatamente posteriores apenas se mencionarán y podemos afirmar, sin temor a dudas, que realmente quedaron suprimidas. Siempre ha llamado la atención de los historiadores - a veces con verdadera sorpresa $^{3}$ - que, a pesar de la trascendencia de esta decisión — que cabe calificar como verdadero giro político - no hubiera oposición alguna. Quizá lo más adecuado para encontrar una respuesta sería prestar atención a las élites caballerescas que encabezaban los concejos. Sin duda, habrá que profundizar mucho más en el estudio de su relación con las hermandades, pero, de momento, lo que podemos hacer es destacar que en la nueva situación abierta en 1325 la palanca hermandina no era eficaz ni tenía demasiado interés para asegurar sus afanes. En realidad, no había conseguido ni estabilidad ni orden y cabe pensar que, seguramente, había pasado su hora, una vez que el rey tenía en sus manos el poder efectivo. Probablemente, a ojos del trono, se veía más bien como molestia y mal recuerdo de unos tiempos difíciles que se daban por zanjados ${ }^{4}$.

Así las cosas, podemos traer a colación una carta del concejo de Valencia de Don Juan, fechada en 1350, en la que recurre a un precepto de la Hermandad de 1295 para ayudar a la ciudad de León ${ }^{5}$. Nos permite esto entender que el entramado de aquellas grandes corporaciones generales no se esfumó por completo, pero no nos engañemos, de las viejas hermandades nada quedaba, salvo el recuerdo y pequeños rastros aprovechables para la labor de algún leguleyo. En cambio, lo que realmente persiste, como no podía ser de otro modo, es la tendencia asociativa, a escala más o menos local, en defensa de intereses, propiedades y, en definitiva, seguridad. Será precisamente en la primera mitad del siglo XIV cuando se vayan articulando y consolidando las hermandades que mucho después se dirán viejas, de Toledo, Talavera y Villareal ${ }^{6}$, y había otras

3 Tal es el caso de MÍNGUEZ FERNÁNDEZ, 1990: 556.

${ }^{4}$ En junio de 1326 la corte regia daba por nulas las demandas que pudiera haber contra Burgos, incluyendo las que fuesen «por razón de hermandad». AM Bu, n. ${ }^{\text {o }} 2697$ y Libro de Privilegios, f. 30. Ya en el trabajo clásico sobre las hermandades de SUÁREZ FERNÁNDEZ, XVI (Buenos Aires, 1951): 28, se señalaba la posibilidad de que las hermandades no fueran, para la mentalidad de Alfonso XI, más que un mal recuerdo.

5 RUIZ DE LA PEÑA, 1978: 155-56, indica que esta carta, conservada en el AM Le, es un testimonio de la «enorme vitalidad» que todavía conservaba la noción hermandad.

${ }^{6}$ Sobre la primera, ver mi libro SÁNCHEZ BENITO, 1987, y mis artículos más recientes indicados en la bibliografía. 
agrupaciones de ámbito estrictamente local. Desde luego, nada tenían que ver con las que había derogado Alfonso $\mathrm{XI}^{7}$.

De este modo, no es demasiado sorprendente que cuando lleguen tiempos de desestabilización y guerra se empezara a intuir desde el trono la posibilidad de recurrir al asociacionismo hermandino como instrumento de utilidad para el ejercicio del poder regio. Sabemos, en este sentido, que, en mayo de 1367, Pedro I escribió a Murcia para que hiciera hermandad: «Tengo por bien fazer hermandades entre vosotros porque guardedes cada uno en vuestra comarca que non roben ni fagan mal ni daño alguno», aunque no se concretó nada y lo único que quedaba claro es que «fagades luego hermandades en la manera que vieredes que se puede fazer $\iota^{8}$. Es evidente que esta iniciativa tenía mucho que ver con la condición fronteriza del territorio murciano, con las especificidades, en fin, que tenía la región, y se deducía de las conveniencias del soberano en tiempos de violencia. Pero lo más importante es que no pretendía otra cosa que asegurar el control de este espacio en sus manos. Esto es lo principal. Así pues, la noción de hermandad se convertía en una herramienta que, en momentos difíciles, no solo proporcionaba apoyo político e, incluso, la posibilidad de contar con una fuerza armada, sino que permitía articular el espacio de forma adecuada a la proyección del poder monárquico. En todo caso, debe verse como una solución coyuntural y quizá apresurada, que no consiguió consolidarse y posiblemente ni siquiera pudo arrancar. Después, y con una orientación netamente petrista, apareció en Asturias una agrupación de villas y caballeros, llamada «hermandad, ayuntamiento, confederación e jura»?

Mientras tanto, en el bando contrario, Enrique de Trastámara dejó claro su rechazo a estas instituciones en las Cortes celebradas en 1367: «Que quanto agora, por algunas cossas que son nuestro seruiçio, que non cunple que se ffagan las dichas hermandades $\rangle^{10}$, por más que, en plena guerra, la violencia proliferaba sin freno por todo el reino. D. Enrique, en fin, no veía en ellas un instrumento útil para sus objetivos, que no eran otros que imponerse en el conflicto.

Sin embargo, la historiografía se ha fijado mucho más en el ordenamiento de justicia de las Cortes de 1351, al comienzo del reinado Pedro I. Dicho ordenamiento - lo han repetido diferentes historiadores innumerables veces - habría sido el cimiento jurídico de las hermandades que — como veremos dentro de

7 También con fines de lucha contra malhechores podríamos alegar, entre otras, la integrada en 1345 por Alcalá la Real y Priego. JUAN LOVERA, 87 (Jaén, 1976): 71-78.

${ }^{8}$ Documento publicado por MOLINA MOLINA, 1978: 211-12 y por DÍAZ MARTÍN, 1997, vol. 4, n. ${ }^{\circ}$ 1378. De alguna manera se han referido a esta hermandad SUÁREZ FERNÁNDEZ, XVI (Buenos Aires, 1951): 38-39 y PASCUAL MARTÍNEZ, III (Murcia, 1977): 165-66, aunque ambos adelantan la fecha cuatro años.

9 BENITO RUANO, 1971; 33-34. Decía este autor, recordando a Caveda Nava, que más parecía el pronunciamiento de un partido.

10 REAL ACADEMIA DE LA HISTORIA, 1861-1903, vol. 2: 149-50. 
un momento - irán surgiendo en la segunda mitad del siglo XIV ${ }^{11}$. Claro que conviene ser prudentes en este aspecto. Realmente, lo único que hacía la referida normativa era regular el apellido, canalizando la colaboración de los núcleos poblados próximos cuando tenían que ir tras los malhechores.

Sea como fuere, cuando en las Cortes de 1369 se promulgaron nuevas normas de justicia, poco innovadoras con respecto a las ya vigentes, encontramos una frase que no aporta detalle alguno, pero reconoce que en el reino había hermandades, aunque fuese en ámbitos limitados y sin el reconocimiento efectivo del trono: «Pero que por este ordenamiento non dexen de guardar e vsar de la hermandat $\rangle^{12}$. No hay noticias certeras que puedan servirnos de apoyo, pero se trataría, sin duda, de hermandades de ámbito local mediante las cuales ciertas ciudades intentarían apoyarse unas a otras coordinando entre ellas el tradicional apellido.

Poco después, en las Cortes de 1370, aprobó Enrique II que se hicieran hermandades en el reino con el fin específico de asegurar el orden, de modo que «cada comarca que den tantos omes de cauallo e de pie quantos cumpla para guardar la tierra de robos e de fuerças e de males». Para cumplir tales objetivos se basaba una vez más en el apellido, confiaba en los alcaldes ordinarios para impartir justicia y únicamente pretendía lo que se ha indicado: disponer hombres armados en cada población. No iba más allá, carecía de estructura organizativa y hasta, quizá, «se mantuvo más en la teoría que en la práctica» ${ }^{13}$, aunque, de todos modos, sabemos que llegó efectivamente a la ciudad de Toledo $^{14}$. En todo caso, lo que se estaba haciendo era abrir la puerta para el desarrollo ulterior de hermandades de carácter general, impulsadas desde el trono para el cumplimiento de sus fines políticos.

Juan I, al llegar al poder en 1379, se limitó a confirmar lo ya hecho por su padre, que seguía vigente, pero nada podemos averiguar acerca de la verdadera vitalidad que tuviera. No es posible seguir rastro alguno, así que debemos entender que, al carecer por completo de estructura orgánica, la realidad de la institución en estos años era más un deseo que otra cosa; pero un deseo no

11 SUÁREZ FERNÁNDEZ, XVI (Buenos Aires, 1951): 38. Destacaba que esta normativa ponía a disposición de la justicia 20 jinetes y 50 peones en las poblaciones de alguna relevancia, parte de los cuales debían estar prestos a salir en armas. En esta misma línea, GONZÁLEZ MÍNGUEZ, 78-79 (Zaragoza, 2004a): 24.

12 REAL ACADEMIA DE LA HISTORIA, 1861-1903, vol. 2: 164-67. Citado por GONZÁLEZ MÍNGUEZ, 78-79 (Zaragoza, 2004a): 393-94; 2004b: 25. El autor se refiere en estos mismos trabajos a la decisión enriqueña de 1467 en contra del reconocimiento de las iniciativas hermandinas.

13 SUÁREZ FERNÁNDEZ, XVI (Buenos Aires, 1951): 41. La norma legal en REAL ACADEMIA DE LA HISTORIA, 1861-1903, vol. 2: 186-87. Ya PUYOL Y ALONSO, 1982: 41-42, recogía el texto del ordenamiento que se cita.

${ }^{14}$ AM To, Becerro Antiguo, fs. 12v-13r. 
relegado del todo al olvido ${ }^{15}$. Por eso, los procuradores se acordarán de ella, y el rey - en circunstancias otra vez muy difíciles - querrá darle nueva vida en las Cortes segovianas de $1386^{16}$. Hay que pensar, por lo tanto, que, en tal situación, el trono valora la hermandad como instrumento de utilidad, y no precisamente para reprimir vulgares ladrones. En cada ciudad o villa estaría disponible una tropa de veinte jinetes y cuarenta peones, repartidos por turnos a lo largo del año, y desde luego, el apellido volvía a ser de nuevo el eje vertebrador de su actividad. Hasta se llega a decir que las gentes acudiesen con armas a sus labores. Cabe afirmar, en términos generales, que ni la idea variaba con respecto a lo dispuesto en 1370, ni se añadía nada sustancial en lo que se refiere a los criterios organizativos. Por cierto, digamos de pasada que las mismas cifras de caballeros y peones de cada localidad se volverán a repetir en ocasiones posteriores y, un siglo más tarde, se dirá también que los labradores fuesen al campo armados.

Sin embargo, sabemos algunas cosas interesantes de lo que fue la aplicación práctica de lo ordenado en 1386. Podemos empezar diciendo que la decisión regia, incluyendo la normativa de las Cortes, llegó a Burgos ${ }^{17}$, pero no hay de allí más detalles. En el Señorío de Villena se desplegó desde fines de octubre de 1386. Cierto es que entre aquellos concejos había unos lazos tradicionales y también lo es que el señor tuvo un protagonismo cierto ${ }^{18}$, pero fue el impulso regio lo que dio vida a la asociación de dichas villas, siguiendo lo dispuesto en las Cortes de Segovia que se celebraban por entonces. Y, naturalmente, hay que tener muy en cuenta las condiciones de inestabilidad política del momento.

Se unieron de esta manera los concejos del Marquesado, al servicio del rey y del señor. La finalidad que tenían no era otra que apoyarse entre ellos, recurriendo al apellido en cuanto llegaba noticia de asaltos y alteraciones. Así las cosas, la manera de actuar es perfectamente previsible: en caso de actos violentos saldrían los del lugar más cercano contra los causantes, y a continuación, sucesivamente, los hombres de las poblaciones cercanas, enfrentándose a ellos y ejecutándolos sin más en el mismo lugar, «a la ballesta o enforcados». Por lo tanto, la entidad que aquí nos ocupa debe entenderse como la aplicación en estos territorios de la organización hermandina que pretendía el rey $\mathrm{y}$, por supuesto, al igual que en 1367 o en 1370, no estaba enfocada a perseguir pequeños delincuentes rurales; era más bien un instrumento de defensa destinado a

${ }_{15}$ Se menciona de pasada en Cortes de 1385, REAL ACADEMIA DE LA HISTORIA, 1861-1903, vol. 2: 323.

16 REAL ACADEMIA DE LA HISTORIA, 1861-1903, vol. 2: 337-41. Cita SUÁREZ FERNÁNDEZ, XVI (Buenos Aires, 1951): 347-48.

${ }^{17} \mathrm{AM} \mathrm{Bu}, \mathrm{n}^{\circ} 2525$ y 53 y Libro de Privilegios, fs. XLV-XLVII.

18 MITRE FERNÁNDEZ, XXX (Murcia, 1969): 55.62. TORRES FONTES, 23 (Villena, 1973): 32-39. PRETEL MARÍN, 1 (Albacete, 1979): 219. PRETEL MARÍN y RODRÍGUEZ LLOPIS, 1998: 187-188. 
hacer frente a escaramuzas y asaltos, característicos de la forma de guerrear a escala local en la época. No de otro modo cabe interpretar la previsión para que, en caso de guerra o enfrentamiento, los ganados se refugiasen en términos de las otras villas sin necesidad de pagar derechos. Conviene resaltar, finalmente, que en el plano institucional se decidió nombrar cuatro alcaldes, dos del obispado de Cuenca y otros dos del de Cartagena ${ }^{19}$. Sabemos también, y es menester tenerlo presente, que, rápidamente, cuando todavía no se habían cerrado las Cortes, el despliegue hermandino llegó a Alcaraz — proyectándose seguramente desde allí hacia el Campo de Montiel- y también quedó involucrado el ámbito murciano ${ }^{20}$.

Sin duda, es completo el paralelismo entre las dos etapas sucesivas que hemos visto, 1370 y 1386. En ambos casos el trono pretende utilizar las hermandades en momentos difíciles, haciéndolo de tal forma que en los distintos rincones del reino debían agruparse las localidades de ciertos ámbitos bien definidos — como el Señorío de Villena - o en torno a núcleos más importantes — Toledo, Burgos o Alcaraz-, aprovechando su centralidad y trascendencia territorial. Sin embargo, no se creó ningún tipo de esquema orgánico, más allá de la mera colaboración entre las distintas localidades en torno al funcionamiento del apellido. Además, si era fácil imponer el principio de la agrupación de poblaciones en sectores sometidos a una misma jurisdicción o donde hubiera una autoridad bien visible - como el marqués de Villena —, las cosas se complicaban cuando no era así. Por consiguiente, aunque los textos normativos tenían vocación de generalidad y abarcaban pretendidamente todo el reino, en el mejor de los casos los esfuerzos que realmente se hicieron no fueron más allá del ámbito regional y se llevaron a cabo de forma desigual. Se entiende perfectamente, en definitiva, que, en ausencia de un mínimo dispositivo, las dificultades de articulación eran prácticamente insuperables y no había forma de asegurar su perduración en el tiempo. Quede claro, no obstante, que en 1386 se había conseguido un cierto avance en este sentido, mucho mayor, desde luego, que en 1370.

Justo tras la muerte de Juan I, se enviaron cartas reales a las ciudades - y, desde luego, a Murcia - argumentando que «en los tales tienpos algunos malos omes suelen faser mouimiento, así en rrobar los caminos como en faser otros malefiçios»y, para evitarlo, «ordené que se reformasen las hermandades de todas las çibdades e villas e lugares de los mis rregnos, segund lo fueron en los tienpos pasados $\rangle^{21}$. Así que, una vez más, desde el poder central se volvía a

19 BN, manuscrito 13102 , fs. 122-30.

${ }^{20}$ Referencias al respecto en PRETEL MARÍN, 1978: 40 y apéndice XII. LÓPEZ SERRANO, 1997: 347-48. SOLER GARCÍA, 1984, vol. 2: 226, publica una carta, interesante a este respecto, del concejo de Murcia, conservada en el Archivo Municipal de Villena.

21 AM Mu, Actas Capitulares, 1390-VI-21/1391-VI-23, fs. 165-66. El texto prosigue diciendo «por que vos mando que luego en punto, vista esta mi carta, formedes e conçertedes 
poner en vigor esta institución para garantizar la seguridad y controlar el territorio desde el trono, concertando villas y ciudades a partir de un núcleo principal en cada ámbito (como era el caso de Murcia, por ejemplo). Más tarde, en las Cortes de 1391, se dispuso que, mientras durase la regencia, se mantendrían las hermandades, «salvo tenprar e emendar cosas rrazonables» "2 $^{22}$ lo cual nos lleva a pensar, por un lado, que conservaban un cierto pulso y, por otro, que, quizá, a veces, surgirían ciertas aristas en sus maneras. Claro que, mientras tanto, y con independencia de lo anterior, hubo diferentes iniciativas locales desde Asturias a Andalucía.

\section{LA ÉPOCA DE JUAN II: MOVILIZACIÓN DE RECURSOS BÉLICOS E INICIATIVAS LOCALES}

Llegamos así a fines de la primavera de 1421. Por entonces, el infante D. Enrique había movilizado buen número de lanzas y la corte regia se sentía amenazada. Hubo que tomar medidas y, para evitar que se hiciesen más llamamientos contra el trono y se pudiera llegar a perder por completo el control de un extenso territorio, se pensó de nuevo en la hermandad. A Burgos llegó la orden regia para que se hiciese $e^{23} \mathrm{y}$, desde allí, se enviaron mensajeros para procurar su extensión. Se sabe que por lo menos Palenzuela y Belorado participaron y ni que decir tiene que el procedimiento de actuación previsto no era otro que el apellido ${ }^{24}$.

Lo mismo exactamente se repetirá otras veces en el curso de la turbulenta historia política del reinado de Juan II. Así, en 1446, e igualmente por impulso regio, Madrid, Alcalá, Torrelaguna, Guadalajara, Uceda, Talamanca y Alcolea se agruparon contra los contrarios al rey que estaban situados en Atienza y Torija, sumando sus fuerzas a las órdenes del capitán que el monarca pensaba enviar. Al fin y al cabo, se trataba únicamente de enviar tropas a las órdenes del trono ${ }^{25}$, pero no parece que, al menos los madrileños, pusiesen demasiada dili-

vuestras hermandades vnos con otros, e pongades muy buenas guardas». Consultado en internet (febrero de 2020): https://www.archivodemurcia.es/p_pandora4/viewer.vm?id=1414398 \&view=archivo\&lang=es Si se apresaba a alguien se debía entregar a merinos y justicias ordinarias. También a Baeza y Sevilla llegaron cartas similares, RODRÍGUEZ MOLINA, 2002: 324-31. Indudablemente la iniciativa permanecía viva en 1392.

${ }^{22}$ REAL ACADEMIA DE LA HISTORIA, 1861-1903, vol. 2: 489. ÁLVAREZ DE MORALES, 1974: 107. Mucha razón tiene SUÁREZ FERNÁNDEZ, 1977: 348, cuando señala que las disposiciones de Cortes de 1390 sobre ligas y confederaciones no tienen nada que ver con la hermandad. A veces se han interpretado en sentido contrario, como una prohibición de la misma, y nunca hubo tal.

${ }^{23}$ La carta real iba dirigida a la ciudad y todo su obispado. AM Bu, n. 2631.

${ }^{24} \mathrm{AM} \mathrm{Bu}$, n. $^{\circ} 2631$ y 59. Ver algo al respecto en ÁLVAREZ DE MORALES, 1974: 111-12. Y, más recientemente, SEBASTIÁN MORENO, 2017: 376 y 389; 2019: 53-76.

${ }_{25}$ Del 4 de noviembre de 1446 data una orden regia indicando que, por mandato del soberano, «vosotros auedes fecho hermandad» y urgiendo para que así se hiciere efectivamente. El 
gencia a la hora de movilizar a las fuerzas que les correspondían. Dos años antes el rey había escrito a León para que hiciera un hermanamiento ${ }^{26}$, también en momentos de dificultad, y, en las Cortes de 1447, se habló de una hermandad formada por las villas y lugares de Valdesgueva debido a que los adversarios del soberano les hacían toda clase de daños y usurpaban rentas reales. En esta ocasión, la corona aceptó expresamente que otros núcleos de población pudieran hacer lo mismo ${ }^{27}$.

Si retornamos a Madrid, constatamos que, de nuevo, en 1453 volverá el trono a recurrir al mismo procedimiento, esta vez contra los enemigos que estaban encastillados en Atienza: «E yo enbié mandar que fiziesedes hermandad para tener e sostener la gente de armas que yo mandé que estouiesen e es mi merçed que estén en el cerco». Como en la ocasión anterior, la villa madrileña ponía toda clase de excusas y dilaciones para preparar los efectivos arma$\operatorname{dos}^{28}$. No obstante, la mencionada hermandad estaba en funcionamiento y sabemos que alguna junta se hizo, así que llegó a tener cierta articulación más allá del mero repartimiento de tropas ${ }^{29}$.

En los ejemplos de los años cuarenta y cincuenta que acabamos de exponer, al igual que en el caso burgalés anterior, no se observa otro objetivo que enfrentarse a los autores de todos estos males y, si evidentemente la inestabilidad política es siempre el telón de fondo, la razón verdadera es el interés político y estratégico del rey, y su necesidad, a veces verdaderamente imperativa, de imponerse en determinados puntos del reino. La hermandad se entiende como un recurso de guerra y, más que eso, un medio para controlar territorios, cuando las escaramuzas, cabalgadas y allegamientos de gentes armadas proliferaban por doquier. Al fin y a la postre, de esta manera se hacía la guerra en un universo político definido por la pugna de facciones y en el que los distintos nobles, formando con unos o con otros, lo que buscaban era reforzar sus posiciones en todos los sentidos. Al mismo tiempo, debemos anotar muy bien que se trata en todos los casos de iniciativas muy coyunturales, forzadas por situaciones de apremio y, por más que a veces se pueda pensar en términos más generales como ocurre en 1386, por ejemplo, y mucho menos en el reinado de Juan II-,

documento está publicado en DOMINGO PALACIOS, 1907, vol. 3: 59, 71-73, 75, 83. En 1449 hubo nuevos llamamientos para colaborar en el sitio de Torija a las órdenes de Iñigo López de Mendoza, enviado por el rey. LOSA CONTRERAS, 1999: 477, nota 605. GONZÁLEZ MÍNGUEZ, 2004b: 30. ÁLVAREZ DE MORALES, 1974: 115.

${ }^{26}$ MARTÍN FUERTES, 1990, vol. 1: 338.

27 REAL ACADEMIA DE LA HISTORIA, 1861-1903, vol. 3: 548-49.

${ }^{28}$ DOMINGO PALACIOS, 1907, vol. 3: 103. Al poco, dos meses más tarde, otra orden de movilización dirigida contra Escalona no menciona hermandad alguna.

${ }^{29}$ Hay una referencia de fines de enero de 1453 sobre la designación en el concejo madrileño de Benito de Valladolid para acudir, junto con los procuradores de otras villas y ciudades, a una junta de hermandad en Ayllón, PUÑAL FERNÁNDEZ, 2005, n. 4032. 
el alcance que tienen no pasa de lo comarcal o regional. Realmente, en ningún momento el dispositivo adquiere una organización, ni siquiera elemental, más allá de coordinar el apellido y movilizar jinetes y peones con fines concretos. De este modo, aunque sea posible encontrar en la documentación el intento de establecer algún alcalde, nunca se llega a entrar de verdad en el tema fundamental de la jurisdicción, y en ningún momento se contempla otra cosa que no fuese la justicia ordinaria.

Ahora bien, más allá de las iniciativas que pudiera tener la corte regia, en diferentes lugares se estaban ensayando otras hermandades. A principios del siglo XV, por ejemplo, una se había formado entre Villena, Sax y varios lugares de la Corona de Aragón, «por razón de algunos malos omes almogávares que salteaban e furtavan los omes $\rangle^{30}$. Es lo cierto que, en este entorno fronterizo, tales sucesos no fueron raros a lo largo del tiempo y los «omes malos almogávares» aparecen una y otra vez en pequeños grupos, haciendo asaltos con la mayor rapidez posible y contando con el apoyo de informadores, encubridores y caballeros de los castillos comarcanos. En esta misma línea, no podrá sorprendernos que, algo más al norte y bastantes años más tarde, en 1471, se propusiera a Cuenca desde Albarracín un hermanamiento para evitar los no pocos actos violentos que estaban teniendo lugar en los alrededores de la frontera, incluyendo cabalgadas mutuas de nobles y concejos ${ }^{31}$.

Iniciado el reinado de Enrique IV, en 1460, las villas de Moya y Requena enviaron mensajeros a Cuenca para constituir hermandad con un objetivo muy claro que era la seguridad ${ }^{32}$. Para ello, el principio básico debía ser la ayuda

30 SOLER GARCÍA, 1984, vol. 2: 228-29. Este documento, otorgado por Juan Rodríguez de Salamanca, justicia mayor en el Reino de Murcia, prorroga la mencionada hermandad, que llevaba dos años de vida, e indica que si hubiese alguna duda en el tenor de sus capítulos que se los mandasen para que él resolviera. BERGES SÁNCHEZ, 2009: 107, nos lleva mucho más atrás en el tiempo, a 1328, al referirse a un acuerdo entre Albarracín y Molina, que, según nos dice el autor, «no es ni más ni menos que una de las frecuentes juntas o hermandades que a lo largo de los siglos XIV-XV se realizaron entre las tierras de Albarracín y las vecinas poblaciones de Castilla para frenar los abusos de salteadores y bandoleros favorecidos por tiempos de suma inestabilidad política». Efectivamente, hubo acuerdos frecuentes entre poblaciones de ambos lados del trazado fronterizo contemplando toda clase de asuntos concernientes a las relaciones de vecindad, incluyendo el acogimiento de bienes robados, malhechores, paso de huestes, etc. Ya en el siglo XV todo esto se contempla en un acuerdo establecido entre el marqués de Villena y el vizconde de Chelva para hermanar ambas localidades, Utiel y Chelva, de las que eran señores. Véase BALLESTEROS VIANA, 1988: 166, reedición de la de 1899. En todo caso, cabría enumerar varios acuerdos establecidos en este sector fronterizo en los años centrales de esta centuria.

${ }^{31} \mathrm{AM} \mathrm{Cu}$, leg. 199, esp. 1, fs. 5r-v. En 1476 los Reyes Católicos confirmarán una hermandad formada por varios núcleos castellanos y aragoneses para pacificar la frontera. Tal vez la de 1471 fuese la raíz de esta.

32 AM Cu, 195-1, fs. 14v, 22v-25r. Se publica íntegramente el acuerdo en SÁNCHEZ BENITO, 2012a, vol. 2: 1885-1888. El concejo de esta ciudad llegó a ofrecer recompensa en 
mutua. Cada concejo se comprometía a nombrar escuderos para que, estando siempre alerta, actuasen con prontitud contra los que hubiesen cometido cualquier daño. En estos seguimientos estaban autorizados a penetrar, cuando hiciera falta, en los términos de las otras localidades hermanadas. Después, debían entregar a los capturados a la justicia del lugar en el que hubieran cometido los desmanes, la cual actuaría según «los remedios e rasones quel fuero e derecho dispone». La hermandad recién nacida no contaba, pues, con ningún organismo común, los escuderos actuaban en su tierra y las competencias judiciales no salían de las justicias ordinarias. En caso de necesidad se podía recurrir a los aldeanos convocando apellido. Así pues, era una respuesta a la inseguridad fronteriza y, en particular, a la acción de señores y caballeros, de cuyos intereses dependía la violencia que ejercían las bandas que se movían por la zona $^{33}$, pero no había ninguna intención de ir más allá, ni mucho menos poner límites a las jurisdicciones concejiles. Aunque no debió prolongarse, nada sabemos acerca de su duración y, resumiendo las cosas, no es más que una alianza determinada por las circunstancias y equilibrios políticos de la región. Este ejemplo es buen indicio de una realidad: a fines del reinado de Juan II y comienzos del siguiente se estaban constituyendo hermandades más o menos locales, con muy poca o ninguna dotación institucional y, estrictamente, en función de los aconteceres de cada zona, aunque, desde luego, la inestabilidad del reino en su conjunto es la clave. Por otra parte, una conclusión que también hemos de extraer es que la intervención de los poderosos en la competencia política se canalizaba, entre otras cosas, a través de la acción de grupos armados, cuyos movimientos y depredaciones no se entienden si no pensamos en los referidos nobles. Lo que hacían en realidad era una forma de guerra, «guerra en migajas» si se quiere, en cuyo desarrollo el botín es siempre objetivo primordial. No debemos imaginar siempre la presencia de ejércitos numerosos y bien dispuestos. En estas condiciones, se hacían robos, se causaban muertes y heridas, también había secuestros, y todos lo entendían como verdaderos delitos sobre los cuales cabía recurrir a la ley y la justicia. Cuestión distinta es que los jueces pudieran verdaderamente entender de tales hechos y ser mínimamente eficaces.

este mismo año, 1460, por la captura de los malhechores que actuaban a la sombra de los montes. AM Cu, 195-1, f. 8v. En algún momento se alude a la acción de «algund señor o cauallero poderoso» apoyando directamente a estas bandas, que se movían fácilmente por los barrancos, iban de una jurisdicción a otra y contaban siempre con la proximidad de la Corona de Aragón. Poco después, al incrementarse la inestabilidad política, el problema se hará más perentorio.

${ }^{33}$ En los textos se habla de «malfechores, omiçidas, ladrones, robadores», pero estas expresiones no deben engañarnos sobre la naturaleza de estas bandas y el alcance del problema. Algo he tratado sobre esta temática en mi artículo SÁNCHEZ BENITO, 5 (Ciudad Real, 2016): 54-71. 
Si volvemos la vista a Burgos, una vez más, y nos atenemos a lo que indica un autor ya citado, Javier Sebastián, nos encontramos con que el concejo burgalés había enviado mensajeros a localidades comarcanas en 1432, con el deseo expreso de poner en marcha alguna organización hermandina dedicada a tareas de seguridad. Tal vez ni siquiera llegó a constituirse, pero la idea no se borró de la mente de los dirigentes municipales, del mismo modo que permanecía la sensación de inseguridad. Por eso, en 1441, los regidores volvieron a insistir en lo mismo y, en 1450, tuvieron que reaccionar a los actos de violencia que hacía en Palenzuela el mariscal de Castilla. En esta última oportunidad, tras proponer al soberano la organización de hermandad, dieron comienzo al proceso convocando primero a las villas próximas y llegando, a continuación, hasta Valladolid y Palencia ${ }^{34}$. Dos años antes podemos encontrar otro ejemplo interesante y suficientemente documentado. Por entonces dio comienzo una asociación que integraba, al principio, a las ciudades de Zamora y León, sumándose, a continuación, Astorga y Toro. Servía para movilizar efectivos que asegurasen la defensa mutua y nos muestra claramente la faccionalización de la política, señalando como enemigos a los vecinos de las ciudades hermanadas que no siguiesen los objetivos propuestos ${ }^{35}$.

Es seguro que en la Castilla de mediados del siglo XV proliferaron los acuerdos locales o regionales de diversa índole, siempre de la mano de la inestabilidad y la violencia. Cierto es que dichas iniciativas tenían antecedentes, como ya sabemos, y no está ausente en ellas la preocupación de los concejos por la integridad de sus territorios, ni tampoco el uso de la violencia como una parte de la acción política de la alta nobleza.

En las Cortes de 1451, se dijo que en «algunas çibdades e villas e logares de vuestros rengos se han fecho e fazen hermandades para rresponder los vnos a los otros e restituir los dichos dannos e robos e tomas e muertes». La petición de los procuradores recibió la aprobación regia, aunque de manera condicionada, pues «deuense limitar los casos para que se deua fazer hermandat»» ${ }^{36}$, de modo que dichas hermandades solamente podrían actuar para evitar delitos y tomas de rentas reales, pues para «otras cosas podría cabsar inconuenientes». ${ }^{37}$ Es cierto que la postura del rey está cargada de recelos hacia los pactos her-

34 SEBASTIÁN MORENO, 2017: 377-378.

35 Dio a conocer esta hermandad MARTÍN FUERTES, 1990: 337-349.

${ }^{36}$ PUYOL Y ALONSO, 1982: 44-47. Teniendo en cuenta esta frase se refirió el autor a la ambigüedad del rey, a tal punto que la contestación regia «podía estimarse una verdadera negativa». Después, distintos historiadores han insistido en esta misma idea, entendiendo entonces que la actitud de Juan II con respecto a la hermandad fue oscilante.

37 REAL ACADEMIA DE LA HISTORIA, 1861-1903, vol. 3: 608-09. Decía VALDEÓN BARUQUE, 1979: 168, que, en las Cortes de 1451, «se pidió expresamente a Juan II la constitución de hermandades para la defensa del patrimonio regio, amenazado por la expansión señorial abusiva». Hay que ver esto con prudencia, pero es cierto que la expansión de los seño- 
mandinos de iniciativa local, pero no es ambigua. Se consideraban instrumento de utilidad, siempre y cuando respondiesen a la iniciativa de la Corona. No si surgían aquí o allá sin ningún control. Además, todos eran conscientes de que, por su propia naturaleza - como alianza laxa de sujetos políticos-, las hermandades de la época tenían muy poca institucionalización y eran difíciles de manejar y sostener en el tiempo. Desde estas premisas hay que entender, creo yo, la política monárquica con respecto a las hermandades en esta etapa.

La cuestión es - según lo que hasta ahora llevamos hablado- que podían surgir de propuestas locales, como acabamos de ver, en cuyo caso tendrán siempre alcance limitado; o bien, el proyecto estaba relacionado con el soberano, y entonces se entendía como un instrumento para la acción de la monarquía. Estas últimas, en su praxis, no superaban tampoco la escala regional y, en los casos que hemos visto en el reinado de Juan II, tienen unos objetivos muy determinados, pero, como parte de la acción regia cabía plantear que llegasen a todo el reino, y entonces estamos en presencia de una hermandad general. De todos modos, en un caso y en otro, las hermandades se entendían, en la práctica, de una forma temporal.

\section{ARTICULACIÓn DE LA HERMANDAD Y DOMINIO DEL TERRITORIO}

No mucho después, tras el ascenso al trono de Enrique IV, se observa un cambio que importa mucho subrayar. En el transcurso del año 1456 el soberano ordenó la agrupación de una nueva propuesta hermandina centrada en la meseta norteña castellana. Estaba formada por Segovia, Burgos, Valladolid, Palencia, Ávila, Arévalo, Roa y Aranda. Como hemos visto, no era la primera vez que se actuaba así desde la corte regia, pero en esta ocasión aparecen nuevos elementos organizativos que antes solamente se observan en las hermandades de Toledo, Talavera y Ciudad Real, donde ya contaban con tanta tradición y solidez que eran pieza esencial en ellas. Me refiero a los llamados cuadrilleros, ya mencionados en 1300, tanto en Toledo como en Talavera, y cuya finalidad consistía en guardar la tierra ${ }^{38}$. Las dos cartas otorgadas en este año por las autoridades municipales de ambas ciudades, a favor de las mencionadas hermandades de los montes, tenían unos fines muy concretos, que consistían en respaldar jurídicamente lo que no era más que una asociación hecha por colmeneros

ríos nobiliarios preocupaba sobremanera a las ciudades en esta época y no podía ser del todo ajena a los pactos de hermandad que hacían los concejos entre ellos.

${ }^{38}$ El documento talaverano de 27 de junio de dicho año en AM Ta, Santa Hermandad, leg. 23, n. ${ }^{\circ}$ 7, publicado en SÁNCHEZ BENITO, 1990: 19, n. ${ }^{\circ}$ 1. El toledano, de 15 de octubre, en BN, manuscrito 13030, fs. 115r-17r, puede leerse en SUÁREZ FERNÁNDEZ, XVI (Buenos Aires, 1951): 55-57. 
acuciados por la inseguridad. Así, estas dos cartas venían a consagrar unos mecanismos de movilización, ya en uso, para que los que se ganaban la vida en la economía montaraz acudieran en armas contra los malhechores llamados golfines, y los cuadrilleros servían para encuadrar dichas movilizaciones. De este modo, su tarea consistía, inicialmente, en ejecutar los llamamientos para que acudieran los colmeneros cuando los malhechores estaban cerca. De esta forma habían surgido a fines del siglo XIII. Más tarde, por evolución, se convirtieron en agentes permanentemente presentes en el territorio con el fin de actuar contra el delito. Lo hacían mediante la persecución, el apresamiento de los culpables y la ejecución de las penas impuestas por los jueces. Cierto es que en estas hermandades viejas eran ellos los que verdaderamente articulaban el dispositivo en el territorio y conseguían que la acción hermandina estuviese continuamente presente en la tierra. Además, la tarea de vigilancia que tenían encomendada y su conocimiento profundo de los aconteceres locales, tenían un efecto claramente disuasorio. Por supuesto, debían tener la necesaria idoneidad y recibían salario. Al mismo tiempo, la evolución que estamos viendo en la trayectoria de los cuadrilleros nos muestra otro aspecto que no conviene dejar en el tintero. Es el paso de la lucha en los montes contra las bandas aguerridas y numerosas de golfines, en cuya proliferación tiene mucho que ver la inestabilidad política de los últimos tiempos del siglo XIII, al control del espacio para imponer el orden que necesitan los grandes propietarios de colmenas en el desarrollo de sus actividades. Por eso, al paso del tiempo, los cuadrilleros se centran, principalmente, en el pequeño delito, y así es en el siglo XV.

Volviendo al hilo de nuestra argumentación en torno a lo que supone la organización de 1456, importa decir que dicha entidad - tan parca en documentos como todas las que llevamos mencionadas - se conoce por una carta que dio a conocer en su día Julio Puyol ${ }^{39}$. En este momento se estaba desplegando la institución, por orden - como hemos dicho - del rey y, en consecuencia, desde el concejo segoviano se expidió dicha carta para que se incorporase uno de los pueblos de su tierra, El Espinar. Al hacerlo, el lugar tenía que proceder al nombramiento de los dos cuadrilleros que le correspondía por tener más de cuarenta vecinos. En realidad, el documento queda en esto, pero nos permite afirmar varias cosas de interés:

a) En primer lugar, hay que destacar que la iniciativa era, como otras veces, exclusivamente regia, y se había empezado a organizar en cumplimiento de sus órdenes.

39 PUYOL Y ALONSO, 1982: 58-61. Breves referencias a esta hermandad en SUÁREZ FERNÁNDEZ, XVI (Buenos Aires, 1951): 43, nota 106. SERRANO, 1943: 168. ÁLVAREZ DE MORALES, 1974: 22. UROSA SÁNCHEZ, 1998: 104. MARTÍN ROMERA, 48/1 (Barcelona, 2018): 101. 
b) Al frente de la nueva corporación estaban cuatro «esecutores, inquisidores e jueces en la dicha hermandad», los cuales dependían totalmente del trono (Pedro de Luxán, asistente de Burgos; Juan de Porres, corregidor de Ávila; Gonzalo Mexía, corregidor de Valladolid, y Diego del Águila, alguacil de Segovia).

c) En la base de la misma había un dispositivo formado por los cuadrilleros (dos en lugares de más de cuarenta vecinos, uno en los de menos, y los inferiores a diez debían juntarse a este fin con la localidad más cercana). Tal dispositivo tenía carácter territorial y estable, del mismo modo que en las hermandades viejas.

d) Había un cierto deseo de duración, pues la carta segoviana estipulaba que cada año los cuadrilleros de cada lugar se debían presentar a la ciudad.

En definitiva, se definían unos dirigentes específicos de la hermandad, del todo relacionados con el trono, y un sistema territorial de seguridad con unos agentes propiamente dichos. Ya no era solo la mera convocatoria del apellido, que, con todo, no quedaba en el olvido. Hay que entender que, cuando los cuadrilleros lo necesitaban, podían llamar en su ayuda a la población, aunque, en la práctica, actuaban en solitario o al frente de pequeños grupos.

Tiempo después, avanzado el mes de septiembre de 1464, documentos de origen municipal ponen de manifiesto que, por orden del soberano, volvían a ponerse en pie hermandades. Comprobamos que así se estaba haciendo entonces en torno a Segovia y también en Cuenca, formando diversas localidades alrededor de cada una. Tengamos muy presente para entenderlo que, por estas fechas, el enfrentamiento político era descarnado, la crispación arreciaba y las tensiones llegaban a todos los rincones de Castilla. Como es lógico, para el rey era imprescindible asegurar lealtades y espacios.

En lo que se refiere a Segovia, hay una carta real enviada a Madrid para que, en cumplimiento de órdenes que ya se habían dado, enviase procuradores en el plazo de unos días para poner en marcha la nueva hermandad. Lo mismo harían, además de Madrid, Sepúlveda, Arévalo y El Real de Manzanares ${ }^{40}$. Por consiguiente, la pretensión de la corte consistía en articular a favor del soberano todo un amplio territorio desde un núcleo principal que ofreciera garantías de lealtad y apoyo. En Cuenca tenemos más datos. Allí, casi al mismo tiempo, llegaron también mandatos regios para formar una hermandad ${ }^{41}$. El papel centralizador del núcleo urbano era similar al que hemos visto en el caso de Segovia y, del mismo modo, habían de acudir otras villas exactamente igual. No nos sorprende que las primeras de esas villas fueran Requena y Moya, con las que ya nos hemos encontrado páginas atrás. Es verdad que más cerca estaba

\footnotetext{
${ }^{40}$ La carta real en DOMINGO PALACIOS, 1907, vol. 3: 153-56.

${ }^{41} \mathrm{AM} \mathrm{Cu}, 196-2$, fs. 11v-16r.
} 
la ciudad de Huete, pero no se podía pensar en ella al estar firmemente en manos de Lope Vázquez de Acuña, totalmente vinculado a Juan Pacheco. El concejo de Cuenca, de la mano del obispo Lope Barrientos, formaba ciertamente al lado del rey y era de fiar en este aspecto mientras el prelado conservase su supremacía local y regional, pero no faltaban adversarios, bien sea en los alrededores como en sus mismas calles. Por eso se pidió que los vecinos jurasen fidelidad al soberano, debiendo alejarse fuera de los muros los que tuviesen compromisos que les impidiesen hacerlo. Se entiende, desde luego, que las redes clientelares de los grandes contrarios al prelado, incluido Juan Pacheco, estaban bien presentes en la sociedad urbana local. Así que, en conclusión, una vez asegurada la ciudad, había que hacer lo propio con todo el entorno, y la hermandad surgió para estructurar este esfuerzo. Muy poco antes se había mandado insistentemente a los conquenses que, junto a las dos villas antes citadas, defendiesen la tierra, y lo hiciesen bajo el mando del obispo Barrientos. Por tanto, en torno a él debía pivotar la organización que se quería impulsar y que, según lo que estamos viendo, debe entenderse como una de las medidas - sin duda importante - que se estaban poniendo en práctica para controlar y defender amplios sectores del reino al servicio de Enrique IV.

En cuanto a la institución recién nacida, no descartemos que se quisiera abarcar la totalidad del país, pero, en la práctica, el planteamiento no podía ser tan ambicioso. Por el momento se trataba, como hemos dicho, de asegurar grandes ámbitos geográficos, partiendo de unos núcleos principales y dignos de la confianza regia. A tal fin, el apellido seguía siendo la fórmula adecuada para movilizar a la gente en armas y, naturalmente, se nombrarían cuadrilleros. Ahora bien, si eran ellos los que tenían que estar presentes en el campo y allí vigilar y reaccionar rápido cuando hubiera alteraciones, la jurisdicción correspondía a unos alcaldes propiamente de hermandad, con residencia en las poblaciones importantes, al modo de las viejas asociaciones de Toledo, Talavera y Ciudad Real. Así que el funcionamiento se basaba en el binomio formado por los tales alcaldes y los cuadrilleros, cada uno con una tarea y un estatus bien delimitados, unos en villas y ciudades, los otros distribuidos en el espacio.

El problema reside en la dificultad que tenía construir el edificio hermandino y — mucho más - consolidarlo. En noviembre de este mismo año, 1464, llegaba a Cuenca una carta real para que el corregidor, junto con Pedro Carrillo, señor de Cañaveras, diese forma a la naciente entidad con todo lo que ello suponía: ordenanzas y oficiales principalmente. Unos meses más tarde, ya en 1465 , todos los indicios vienen a mostrar que no se hacían muchos avances, aunque llegase nueva correspondencia regia. Claro que desde el año anterior la ciudad vivía literalmente en armas, rodeada de amenazas ${ }^{42}$. En este contexto,

${ }^{42}$ Hasta hubo un cerco, del que apenas tenemos referencias breves y no muy directas, cuyo protagonista destacado fue Juan Hurtado de Mendoza, empeñado en hacerse con el núcleo 
Pedro Carrillo de Mendoza tenía hombres para la defensa de la ciudad, pero, como no recibía pago alguno, la abandonó, tras ardua negociación con el concejo $^{43}$. En abril de 1465, Lope Barrientos fue secuestrado a su paso por Belmonte, a instancias de Juan Pacheco, y, finalmente, Juan Hurtado entró en la ciudad, de acuerdo con el rey. Lo que nos interesa es que al paso de estos acontecimientos no hay nada sobre la hermandad, que evidentemente no tuvo protagonismo alguno en todo lo narrado. Hay que esperar a julio para ver la adhesión de la villa de Molina de Aragón ${ }^{44}$. Sea como fuere, la nueva entidad permanecía viva ${ }^{45}$, aunque poco aportaba en la solución de los no pequeños problemas de la vida política local y, quizá, la acosada Corona enriqueña seguía viendo en ella una herramienta que podía ser de utilidad, más para el monarca que para las ciudades. El problema era que el rey no podía sostenerla.

Al terminar el año, se puede afirmar que la hermandad, como idea, había calado en las mentes de todos y tenía la posibilidad de hacerse un hueco en la política del reino, por más que su efectiva implantación fuese, cuando menos, reducida y poco uniforme. A partir de entonces la institución se irá configurando, al paso de las sucesivas juntas generales que se celebraron desde el verano de $1466^{46}$, en las cuales no solamente se hicieron los ordenamientos que habían de regular la actividad hermandina, sino que a ellas llegaban toda clase de asuntos para su discusión y determinación. De esta forma, dichas juntas adquirieron el aspecto de un verdadero órgano de representación.

Al mismo tiempo, y no sin cuantiosas dificultades, se fueron produciendo nuevas incorporaciones y la organización se desplegó alrededor de las ciudades. Para ello, los núcleos principales articulaban a los secundarios y cada ciudad arrastraba a su tierra y a algunos señoríos del entorno, no todos ni mucho menos y más eclesiásticos que laicos. De esta suerte, se fueron definiendo unos distritos provinciales ${ }^{47}$, pero, como decimos, el proceso de integración no fue

conquense a costa del obispo, AM Cu 197-1, fs. 11r-15v y 197-5, f. 67v-75v. Sobre la amplísima problemática que presenta la conflictividad y sus consecuencias en el ámbito conquense, ver mi artículo SÁNCHEZ BENITO, 30 (Salamanca, 2012b): 237-62.

${ }^{43} \mathrm{AM} \mathrm{Cu}, 197-1$, fs. 11v-12r; 197-2, fs. 42r-v, 43v, 45r-v, 51v, 53r-v, 58r-v. Los responsables del concejo eran perfectamente conscientes de que necesitaban contar con la tropa de algunos nobles si querían resistir las amenazas de otros.

${ }_{44}$ AM Cu 5-2 y 197-2, fs. 43r-v, 44v-51r, 59v, 60v.

${ }^{45}$ Lo demuestra el nombramiento de alcaldes en Madrid en septiembre de 1465, por cierto, no sin discrepancias profundas dentro del concejo. Ver en MILLARES CARLÓ y ARTILES RODRÍGUEZ, 1932, vol. 1: 8.

${ }^{46}$ Ha publicado las ordenanzas de estas juntas (Medina, Fuensalida, segunda de Medina, Cantalapiedra y Madrigal), BERMEJO CABRERO, 58 (Madrid, 1988): 343-412.

${ }^{47}$ El que encabezaba Cuenca incluía Sigüenza y Molina, AM Cu 198-2, f. 16r-v. Hace años traté el tema de las provincias en el caso de la Hermandad de los Reyes Católicos en SÁNCHEZ BENITO, 239 (Madrid, 1988): 1509-1528. Aporta una perspectiva interesante en este aspecto el artículo ya citado de MARTÍN ROMERA, 48/1 (Barcelona, 2018): 81-115. 
fácil y «se pusieron grandes penas para que ninguno de los que fueren entrados en las dichas hermandades no pudiese salir» ${ }^{48}$. Ahora bien, lo más importante es que la «Universidad de la Santa Hermandad de los regnos» emerge como un organismo bastante complejo y con fuerte tendencia a la centralización, desde la base - es decir, el medio local, el territorio- a las instancias superiores. Suponía esto que de cada una de las distintas villas y ciudades salían las lanzas que había que poner a disposición del centro decisorio; y, claro, como no faltaron retrasos, impagos, etc., las juntas se atribuyeron la capacidad de revisar los padrones que los concejos usaban para recaudar el dinero ${ }^{49}$. Las quejas, lógicamente, no se hicieron esperar ${ }^{50}$.

Además, los tiempos no podían ser más inestables para todos y los medios armados y diplomáticos de la institución no tardaron en dar muestras de sus limitaciones a la hora de afrontar un conflicto que se manifestaba de una forma muy dispersa. La fragmentación de la praxis política y el consecuente surgimiento de innumerables focos de inseguridad y enfrentamiento, al compás del conflicto general del reino, dificultaba al máximo la acción centralizada de los efectivos hermandinos. En muchas ocasiones no era posible una intervención eficaz y tenían que conformarse con enviar cartas, dar algunas indicaciones y poco más. En la práctica, las ciudades, rodeadas de peligros y cuyas sociedades estaban profundamente penetradas por las redes clientelares de los grandes, tenían que sobrevivir con sus propias fuerzas ${ }^{51}$. Al mismo tiempo, en el interior de la corporación encontraban reflejo las divisiones del reino: "Aunque todos sean juntos, los coraçones son departidos y por esto los pensamientos y las obras non se pueden acordar en uno», se decía en un memorial que hemos citado con anterioridad ${ }^{52}$. No puede sorprender, entonces, que iniciado el año 1468 los diputados generales de la corporación intentaran entenderse con los nobles de una y otra opinión ${ }^{53}$.

${ }^{48}$ Según reza un memorial elevado a Enrique IV, que publica BERMEJO CABRERO, 58 (Madrid, 1988): 341.

${ }^{49}$ Una carta de Alcalá de Henares a Guadalajara, de 6 de octubre de 1466, alude de pasada a la presión fiscal hermandina con una curiosa expresión: «Las tasas puestas por la hermandad de allende los puertos», publicada por LUÍS LÓPEZ, 2007, n. ${ }^{\circ} 65$.

${ }^{50}$ En Cuenca se dirá que se gastaron más de 300.000 mrs. en cosas de la hermandad, AM $\mathrm{Cu}, 198-3$, fs. 10v-11v.

${ }^{51}$ Cuando, a fines de 1466, los murcianos rechazaron el llamamiento para que su ciudad se uniera a la hermandad, argumentaron la lejanía que mediaba entre ambos: «Entre la qual e nosotros está Toledo e su tierra e el marquesado de Villena, e acatando que non podríamos nosotros remediar a vosotros nin vosotros a nos por la distancia». Lo recordaba PASCUAL MARTÍNEZ, III (Murcia, 1977): 167-68.

52 Véase BERMEJO CABRERO, 58 (Madrid, 1988): 342.

53 Véanse, en este aspecto, los capítulos de Tordesillas, de 5 de abril de 1468, AM Cu, leg. 19-1. Hubo, en todo caso, diferentes contactos y, muerto Alfonso, se hizo un pacto en Burgos, AHN - N, Osuna, caja 1868/41. 
Crisis y Restauración de las hermandades enriqueñas: entre las NECESIDADES DE LOS CONCEJOS Y LAS EXIGENCIAS HERMANDINAS

Inevitablemente, al comenzar el año 1469 empiezan a cristalizar las tendencias que en el plazo de pocos meses terminarán liquidando la institución. Se puede esquematizar esta problemática del siguiente modo:

a) En primer lugar, destacaremos los costes que tenían las hermandades y la presión fiscal que era necesario incrementar para soportarlos. En este orden de cosas, hay que pensar, además, que la inestabilidad y la violencia de estos años difíciles tenía repercusiones económicas e, inevitablemente, la protección de las ciudades obligaba a recaudar numerosas imposiciones y repartimientos, aparte de los dedicados a los fines hermandinos. En suma, grandes cantidades de dinero se encaminaban, de una u otra forma, hacia los órganos centrales de la corporación, los vecinos tenían que soportar este peso y, mientras tanto, los concejos necesitaban todos los recursos. Cuando, a comienzos de febrero de 1469, la Junta de Valladolid reclamó aún más, la decisión distó mucho de ser unánime, hubo resistencias muy vigorosas y, a la vez, se presionó con fuerza a las ciudades más díscolas ${ }^{54}$.

b) A estas alturas, había ciudades que, obligadas a valerse por sus propios medios, ante sus muchos retos políticos y económicos, no encontraban compensación alguna al gasto que suponía el funcionamiento de la institución hermandina. Esto está perfectamente documentado en el caso de Cuenca y, seguramente, no era muy diferente en otras muchas, particularmente en las situadas de forma más excéntricas con respecto al eje principal del reino.

${ }^{54}$ En Cuenca, el concejo argumentaba del siguiente modo: «Allende deso en repartimientos pasados e gastos desta Santa Hermandad avemos gastado más de trescientosmill mrs. e nuestro Señor sabe el poco fruto e prouecho que dello se nos ha seguido ... asy que pues en ningund aliuio ni remedio ni prouecho non avemos sentido, antes gasto e trabajo, non sabemos que mengua nos faga non gosar de los benefiçios de la Hermandad». Claro que las respuestas que recibía no eran menos duras: «Entendemos que mucho más perderíades vosotros en non gosar de la libertad de la Santa Hermandad e sus leyes, que ella en perder a vosotros», dijeron los diputados generales. AM Cu, 198-3, fs. 10v-11v y 19r-v. Entre los muchos problemas y distorsiones que presentaba el cobro de las contribuciones destinadas a la hermandad, podemos citar un documento de Guadalajara en el que los arrendadores, entre otras cosas, indican que no podían hacer sus cobranzas en Tendilla ni en Atanzón, comprendidos en el ámbito guadalajareño pero cuyos señores no lo permitían. Documento publicado por LUÍS LÓPEZ, 2007, n. ${ }^{\circ}$ 91. También el clero tenía muchos recelos a estas alturas y el dinero tenía que ver. Se conservan los capítulos de una junta eclesiástica celebrada en Valladolid en la primavera de 1468 en el Archivo de la Catedral de Salamanca, MARCOS RODRÍGUEZ, 1962, n. ${ }^{\circ} 1011$. 
c) Hubo irregularidades en la gestión de los dineros que llegaban a la hermandad y algún caso de corrupción - el tesorero Rodrigo del Rio y otros receptores ${ }^{55}$-, de modo que, si por doquier cundía el cansancio por las cargas económicas, estos hechos venían a ser el colofón. En las Cortes de Ocaña se habló de las muchas sisas, derramas y repartimientos, también del pequeño fruto obtenido con tantos dineros, y todos eran conscientes de las sospechas que sobre todo ello había: «No podemos saber commo y en qué cosa se gastaron tan grandes contías». Se acordó, por lo tanto, que dos personas, debidamente diputadas, tomasen las cuentas al tesorero de la institución ${ }^{56}$.

d) Por último, aunque no sea lo menos relevante, recordemos que tras la muerte del rey Alfonso se registraron cambios políticos de gran calado $\mathrm{y}$, como es natural, no podían dejar de repercutir en una corporación, cuyos derroteros se debían a la naturaleza de la crisis.

En mayo hubo junta en Medina, pero el vigor del esfuerzo hermandino se había debilitado de manera irremediable y la institución perdió gran parte de su prestigio. Iniciadas las sesiones, ni siquiera hubo necesidad de debatir con la dureza que se había empleado unos meses atrás y, por supuesto, ya no llegaban fondos económicos ni se hacían repartimientos. En las ciudades se dejaron de utilizar sus resortes y así se fue vaciando por completo ${ }^{57}$. Si buscamos una vez más el apoyo de la rica documentación conquense, podemos observar que, si en el invierno de 1469 todavía se ponían alcaldes, en la primavera el concejo tomaba lo que quedase en el arca de la hermandad para destinarlo a los muchos problemas de la ciudad ${ }^{58}$. Cierto es, con todo, que entre 1466 y 1469 tuvo dinamismo propio, considerable autonomía y cierta capacidad de acción, pero era resultado de unas circunstancias muy específicas de división del reino.

Durante todos estos años, antes y después de 1469, además de la Hermandad General, también se pudo ver el despliegue de hermandades de carácter local o regional, animadas por las características de dispersión que tiene la

55 AM Cu 198-3, f. 52v.

56 REAL ACADEMIA DE LA HISTORIA, 1861-1903, vol. 3: 794-795.

57 Ya, SUÁREZ FERNÁNDEZ, XVI (Buenos Aires, 1951): 44, se refirió a la desconfianza de los concejos hacia los órganos centrales de la hermandad y a «una crisis interna en la hermandad que dio al traste con la institución» en 1469.

${ }_{58} \mathrm{AM} \mathrm{Cu}, 198-3$, fs. $13 \mathrm{v}$ y $35 \mathrm{v}-36 \mathrm{r}$. Viene a cuento recordar que si, a principios de 1469 , los hombres del conde de Medinaceli tomaron a la ciudad la torre de Alcantud, lo que ponía en sus manos muchas posibilidades de proyección en la tierra conquense, en septiembre el castillo de Arbeteta, también realengo y mucho más importante, se había perdido. Naturalmente, las autoridades concejiles mandaron los refuerzos que pudieron y buscaron toda clase de apoyos, incluyendo la hermandad, pero, al final, solo pudieron contar con sus propios medios y no fueron suficientes para mantener las fortificaciones realengas que hemos mencionado. $\mathrm{AM} \mathrm{Cu}$, 198-2, fs. 21v-22r, 53v, 62r, 68r-v; 198-3, f. 2r, 34r-v, 70r, 71v, 164r, 170v-71v. 
conflictividad de la época y su repercusión en el territorio. Podemos citar, ya lo hemos hecho otras veces, la «Santa Hermandad de la Albogóndiga Guadarrama aquende» (Maqueda, Santa Olalla, Torre de Esteban Ambrán y Puebla de Montalbán). No es posible determinar su origen y solamente podemos alegar que perseguía malhechores y hacía juntas periódicas ${ }^{59}$. Lo único claro es que la influencia de las hermandades viejas de Toledo y Talavera es directa, pero quizá tuviera relación también con la de los «honse sesmos de Segouia e en Madrid e su tierra e en la Sagra de Toledo e Casarruvios e el condado de Mançanares», que aparece mencionada en las ordenanzas de la Junta de Fuensalida y cuya naturaleza realmente no hay forma de concretar. Lo cierto es que no debió servir de mucho a algunos de sus miembros, al punto que Casarrubios del Monte pidió, en 1467, que la Hermandad Vieja toledana llevase hasta allí su jurisdicción ${ }^{60}$. Por cierto, este dato no deja de ser particularmente indicativo en cuanto a la situación que se vivía en la época. Sea como fuere, estas agrupaciones parecen bastante recientes y recogen, al menos en parte, el modelo de las referidas hermandades viejas — como la más antigua, también toledana, de San Martín de la Montiña - y son exponente del sentir del mundo rural en tiempos de inestabilidad política y tribulación.

Después de la crisis de 1469 — se ha dicho en numerosas ocasiones ${ }^{61}$ — aparecieron nuevas propuestas de ámbito igualmente local y regional, cuyo fundamento estaba en la ayuda mutua entre localidades próximas, quizá lo único que podía ser verdaderamente operativo en las condiciones de entonces. La documentación escasea al máximo una vez más, y para entender el fenómeno nos quedaremos con dos ejemplos. Del primero sabemos algo por una carta dirigida desde el concejo de Madrid al de Guadalajara en $1471^{62}$, comunicando que se estaba formando una hermandad que también incluía Toledo, Segovia, Ocaña, El Real de Manzanares y algún otro señorío menor. Nótese que el despliegue geográfico es muy parecido al de la entidad arriba mencionada de Segovia, Madrid, Toledo, etc. La causa por la que surge esta nueva corporación se indica expresamente en el documento y eran los movimientos del reino, así que no debemos engañarnos, aunque se hable de robos, males, daños, el problema es, como siempre, la guerra dispersa tal como se hacía en la época, «la guerra en migajas». Para que tuviera utilidad, los objetivos se simplificaban lo más posible, reduciéndose a dos casos muy concretos: los robos en caminos, despoblados y lugares sin cerca; y las gentes de guerra que «non coman de

${ }^{59}$ AM Ta, Santa Hermandad, leg. 1, n. ${ }^{\text {7 }} 7$.

${ }^{60}$ ADP T, leg. 14, n. ${ }^{\circ} 106$.

${ }^{61}$ Citaremos para mostrarlo, a SUÁREZ FERNÁNDEZ, XVI (Buenos Aires, 1951): 44. Señaló, siguiendo a Enríquez del Castillo, que la Hermandad General fue sustituida por una serie de hermandades dispersas.

${ }^{62}$ Publicada por LUÍS LÓPEZ, 2007: 114. 
balde sobre los labradores». El otro ejemplo, data del año siguiente y la iniciativa es ahora de la ciudad de Ávila, a causa de «los grandes movimientos e desessyones destos reynos»y y sus secuelas que, nuevamente, se califican de «ynsultos e rrobos e males e dapnos». Como en el caso anterior, es también una carta que se remitió al conde de Alba para procurar el ingreso de sus tierras ${ }^{63}$. Quizá ninguna de las dos propuestas llegó muy lejos, pero ponen muy bien de manifiesto el desorden de la guerra. Volviendo por un momento al primero de los dos casos que acabamos de exponer, no dejaré de añadir un detalle de la carta citada que es relevante: «Por esperençia vemos que la hermandat pasada [La Hermandad General] non pudo durar por se aver entremetido a conosçer de otros casos» distintos a los dos que arriba han quedado reflejados. Aquella hermandad tuvo, ya lo hemos señalado, dinámica propia, pero no redujo el miedo de la población ante la amenaza constante de las bandas de guerreros que, irrumpiendo acá o allá, protagonizaban el curso de la guerra.

Mientras tanto, en la primavera de 1469 y, más concretamente, en la Junta de Medina, ya se subrayaba muy bien el papel imprescindible de la Corona, Y si esto ya era así entonces, cuando la hermandad general vuelva a resurgir en 1473, no habrá ninguna duda: la nueva corporación no debía ser más que un instrumento del monarca, «cabeza et señor de todos sus pueblos et el philosofo dice que el rey es corazón et alma del pueblo», como rezan las ordenanzas. La única aspiración es la paz y la justicia del rey, superando así los muchos males «acaescidos et de cada día acaescen de nueve annos a esta parte». Tales son los fines por los cuales, en julio de 1473, se estableció, a petición de los procuradores de las villas y ciudades, y con el consejo de clérigos, el fundamento legal de la nueva entidad, en cuyo texto se insiste una y otra vez en la importancia de la figura regia y en la obediencia y fidelidad a Don Enrique.

Los preceptos elaborados por los procuradores en Villacastín e inmediatamente promulgados por el soberano ${ }^{64}$ son pocos y contundentes. Lo esencial es el binomio alcaldes-cuadrilleros, extendido a todo el reino, como base para garantizar la seguridad e implantar la justicia. Naturalmente, el apellido sigue vigente, aunque organizado de manera que hubiese siempre un número de hombres preparados para ir junto a los alcaldes y cuadrilleros, y con la posibilidad de contar con todos los labradores, que, por si acaso, debían ir a sus labores con lanzas. Se insiste en la disuasión por el temor, aludiendo una y otra vez a la pena de saeta, y se definen bastante bien los casos de hermandad, a fin de evitar dudas sobre el alcance de su jurisdicción. Además de todo esto, hay que destacar que el dispositivo tenía carácter piramidal sobre la base de las ciudades más relevantes, cabecera de reino y obispado, las cuales convocarían al resto y, por debajo, los núcleos urbanos, que reunían a su alrededor los lugares

${ }^{63}$ La carta en CALDERÓN ORTEGA, 2000, n. 59.

${ }^{64}$ Publicados en su día por SUÁREZ FERNÁNDEZ, XVI (Buenos Aires, 1951): 72-78. 
sometidos a su jurisdicción, exactamente igual que en las hermandades generales precedentes.

En consecuencia, la ciudad de Toledo se dirigió por carta a Guadalajara para procurar su ingreso en la institución, aunque la cosa resultó más difícil de lo que podía parecer a la vista del tenor terminante del ordenamiento de Villacastín. Los toledanos enviaron a uno de sus regidores con la oportuna carta, pero, aunque en ella se anunciaba una junta de hermandad a celebrarse en El Espinar, por San Bartolomé de agosto, lo cierto es que nada de lo previsto se cumplió y en octubre tuvieron que mandar nueva misiva ${ }^{65}$. Realmente, no se sabe gran cosa acerca de las actividades de esta nueva entidad. No cabe duda de que entró en funcionamiento en muchos sitios, como Cuenca. En Toledo también ingresó con prontitud el cabildo de la catedral, «por sí e por sus lugares e vasallos», pero en Burgos, aunque llegó el ordenamiento, no se sabe a ciencia cierta si se puso verdaderamente en marcha ${ }^{66}$.

Poco más de un año después murió Enrique IV y, casi de inmediato, la reina Isabel promulgó un nuevo ordenamiento que lo primero que nos deja perfectamente claro es que - con independencia del funcionamiento efectivo que tuviera entonces - la hermandad de ámbito general era un concepto perfectamente vigente y podía servir a los fines de una reina que, imperativamente, necesitaba afirmarse. Y así, efectivamente, tras algunos tanteos muy breves, en febrero de 1475 se procedió a sustituir las ordenanzas de 1473, que apenas tenían año y medio, por otras nuevas, otorgadas en Segovia ${ }^{67}$, exactamente en la misma línea.

Invocando como justificación principal las muchas «muertes, e feridas de omes, e prisiones dellos, e robos, e tomas de bienes, e salteamientos, e otros delitos e malefiçios... de diez años a esta parte», no podía ser más evidente que se quería renovar la hermandad por iniciativa exclusivamente regia, sin que hubiera habido previamente ningún tipo de junta ni petición de procuradores. Simple y llanamente la institución se entendía como un recurso de utilidad, al menos de forma temporal, para que la reina pudiera conseguir sus fines y cohesionar a su alrededor las diferentes ciudades y tierras de Castilla. Lógicamente, no encontramos grandes sorpresas: los alcaldes y cuadrilleros siguen siendo el eje de la entidad y se contempla, por supuesto, la posibilidad de convocar el apellido; también se regulan de forma más precisa los casos de hermandad y se

${ }^{65}$ Ambas cartas en LUÍS LÓPEZ, 2007, n. ${ }^{\circ} 121$ y 123.

${ }^{66} \mathrm{AM} \mathrm{Cu}, 5-3$. AC Toledo, Actas capitulares, año 1473, f. 57. En el de la catedral de Cuenca se conserva el ordenamiento de Villacastín, LÓPEZ GÓMEZ, 2014: 173. También en el AM Bu, n. ${ }^{\circ} 1440$, pero puede verse la noticia sobre la dudosa participación de la ciudad en SEBASTIÁN MORENO, 2017: 382.

${ }^{67} \mathrm{AM} \mathrm{Cu}, 16-4$ (original) y 1145-2 (copia). Publiqué el texto en SÁNCHEZ BENITO, 15 (Madrid, 2002): 238-243. 
prevé la reunión de juntas en cada «çibdad o villa o prouinçia», ahora con carácter regular cada año. Como en 1473, la organización debía articularse en torno a los núcleos urbanos principales, sedes de obispado - ya no se habla de cabeceras de reino- - reuniendo desde ellas a las demás poblaciones y tomando como unidad básica el término jurisdiccional de villas y ciudades.

Hay que esperar poco más de un año para llegar a las Cortes de Madrigal, verdadero gozne en el que culmina este proceso y se abre una etapa de cuyo análisis ya no nos ocuparemos en este artículo. Sabido es que estos meses, antes de Madrigal, fueron singularmente complicados y, aunque el texto de 1475 se hizo llegar al menos a las poblaciones más inclinadas hacia la causa isabelina - como es el caso de Cuenca-, es seguro que no se cumplieron los plazos brevísimos que se habían previsto para que todos ocupasen su lugar dentro del edificio hermandino. Así se explica que en 1476 surgiesen una vez más iniciativas locales ajenas al trono, al menos en Burgos y Tierra de Campos ${ }^{68}$, pero, para entonces, las Cortes de Madrigal estaban a punto de dar comienzo y en ellas se presentó a los procuradores un ordenamiento que, ahora sí, tendrá verdaderas posibilidades de consolidación ${ }^{69}$. Dicho ordenamiento no difiere mucho de lo anterior, parte del mismo planteamiento y en gran medida es copia literal de la legislación precedente. Ahora bien, lo principal no es el tenor de la normativa sino la actuación decisiva de hombres de confianza del trono, que forman el verdadero núcleo de la nueva institución y están dispuestos, en Madrigal y después, a poner en pie eficazmente la hermandad como organización, sin apartarse un ápice de los intereses y objetivos de la Corona. Que se pudiera disponer de estos agentes - principal, aunque no únicamente, Alonso de Quintanilla y Juan de Ortega - y que pudieran negociar y moverse como lo hicieron es la verdadera diferencia con respecto a 1473 y $1475^{70}$. En la primera de ambas fechas no se pudo desplegar una acción política y administrativa comparable, y, en la segunda, la reina Isabel acababa de llegar al poder y lo que ante las condiciones del momento se estaba intentando era prematuro, falto, seguramente, de los mimbres que verdaderamente lo harían posible.

$* * *$

${ }^{68}$ GUERRERO NAVARRETE, 16 (Barcelona, 1986): 550. Esta autora, además de referirse a la propuesta burgalesa, recoge la presentación en dicha ciudad de los capítulos acordados en San Cebrián de Mazote por las villas de Tierra de Campos.

69 REAL ACADEMIA DE LA HISTORIA, 1861-1903, vol. 4: 2-11.

70 «Derroche de habilidad política» por parte de Fernando, muy bien secundado por Quintanilla y Ortega, dice expresivamente MARTÍNEZ RUIZ, 21 (Granada, 1993-94): 394, aunque tal vez haya que pensar más que nada en la habilidad de Quintanilla. Ha biografiado al personaje hace unos años MORALES MUÑIZ, 1993: 72-80, sobre lo relativo a los asuntos de hermandad. 
En suma, en Madrigal, ya lo hemos dicho, culmina el proceso que hasta aquí venimos estudiando y, en consecuencia, quedan a un lado definitivamente las hermandades locales, cuya aparición esporádica pero reiterada hemos ido encontrando a lo largo del tiempo. Sin embargo, es indudable que al terminar las Cortes casi todo quedaba por hacer. Por fuerza se abría una etapa muy laboriosa, en cuyo transcurso, a través de sucesivas juntas reunidas a un ritmo muy vivo (Cigales, Dueñas, Santa María de Nieva, segunda de Dueñas, Burgos y Pinto-Madrid), se formaría la institución que finalmente resultó. Claro que para evitar que, a lo largo de las juntas, la hermandad emprendiese su propia dinámica, como había ocurrido entre 1466 y 1468, las reuniones tenían que hacerse con una sólida dirección. Fue así como, al cabo de este proceso, cristalizó lo que, en definitiva, era una herramienta verdaderamente capaz para el ejercicio del poder regio en muy variados ámbitos, desde la fiscalidad hasta la organización territorial del reino. Como es lógico eran muchos los resquemores - los costes y la carga fiscal, el temor de los poderes ciudadanos y nobiliarios a perder peso, etc.- y las contradicciones abundaban, así que la Hermandad General solo consiguió consolidarse mediante una dificilísima y multifacética negociación, traduciéndose sus resultados en los ordenamientos de las mencionadas juntas ${ }^{71}$. En definitiva, la hermandad entendida como iniciativa concejil ya no tendrá cabida, pero, sin embargo, como herramienta del trono solo podrá permanecer viva hasta 1498. Después será otra cosa bien distinta.

Así pues, la historia de las hermandades castellanas es, a la postre, la historia de un fracaso. Es así tanto si se mira desde el punto de vista de los concejos como si se hace desde el punto de vista del trono, pero las distintas realidades hermandinas que vieron la luz entre 1325 y 1476 no son simple transición a la espera de los Reyes Católicos y su acción supuestamente decisiva en este aspecto. Los procesos de maduración que registran muestran una riqueza y una vitalidad de verdadera consideración, y arrojan luz, como hemos visto, sobre muchos aspectos relevantes, que van desde el despliegue de la acción regia y las características que encierra a las posibilidades políticas que realmente tenían los concejos, pasando por el papel de la violencia en la configuración del poder y las formas que en la época adoptaba la constitución de los aparatos institucionales. Seguramente las hermandades fueron una forma de dar respuesta a retos que para la evolución de la monarquía eran fundamentales y, entre ellos, convendría destacar, quizá, el control y la articulación del territorio.

71 Véase los referidos ordenamientos en GUERRERO NAVARRETE y SÁNCHEZ BENITO, 59 (Madrid, 1989): 643-698. 


\section{Bibliografía}

Álvarez de Morales, Antonio, Las hermandades, expresión del movimiento comunitario en España, Valladolid, Universidad de Valladolid, 1974.

Ballesteros Viana, Miguel, Historia de Utiel, Utiel, Ayuntamiento de Utiel, 1988.

Benito Ruano, Eloy, Hermandades en Asturias durante la Edad Media, Oviedo, La Cruz, 1971.

Berges Sánchez, Juan Manuel, Actividad y estructuras pecuarias en la comunidad de Albarracín (1284-1516), Teruel, CEPAL, 2009.

Bermejo Cabrero, José Luis, «Hermandades y comunidades de Castilla», Anuario de Historia del Derecho Español, 58 (Madrid, 1988): 277-412.

Calderón Ortega, José Manuel, Documentación medieval abulense en el Archivo de la Casa de Alba, Ávila, Institución Gran Duque de Alba, 2000.

Díaz Martín, Luís Vicente, Colección documental de Pedro I de Castilla, Valladolid, Junta de Castilla y León, 1997.

Domingo Palacios, Timoteo, Documentos del Archivo General de la Villa de Madrid, Madrid, Ayuntamiento de Madrid, 1907, vol. III.

González Mínguez, Cesar, «El movimiento hermandino en Álava», En la España Medieval. Estudios en memoria del Prof. D. Salvador de Moxó, Madrid, Universidad Complutense, 1982, vol. I: 435-456.

González Mínguez, Cesar, «Las asociaciones interlocales y las cartas de hermandad como generadoras de derecho», Revista de Historia Jerónimo Zurita, 78-79 (Zaragoza, 2004a): 385-397.

González Mínguez, Cesar, «Poder y conflictos sociales: una visión desde la historia del movimiento hermandino castellano», en Conflicto, violencia y criminalidad en Europa y América, Bilbao, Universidad del País Vasco, 2004b: 13-38.

Guerrero Navarrete, Yolanda, «La Hermandad de 1476 y Burgos. Un factor decisivo en la transformación del poder municipal a fines de la Edad Media», Anuario de Estudios Medievales, 16 (Barcelona, 1986): 533-556.

Guerrero Navarrete, Yolanda y Sánchez Benito, José María, «El proceso constituyente de la Hermandad General. Los ordenamientos de 1476 a 1478», Anuario de Historia del Derecho Español, 59 (Madrid, 1989): 633-698.

Juan Lovera, Carmen, «Hermandad entre Alcalá la Real y Priego (1345)», Boletín del Instituto de Estudios Jienenses, 87 (Jaén, 1976): 71-78.

López Gómez, Érika, Catálogo de la Sección Institucional del Archivo de la Catedral de Cuenca, II. Siglo XV, Madrid / Cuenca, Universidad Autónoma de Madrid / Asociación Seminario de Cultura Lope de Barrientos, 2014.

López Serrano, Aniceto, Yecla: una villa del Señorío de Villena (Siglos XIII al XVI), Murcia, Academia Alfonso X el Sabio, 1997.

Losa Contreras, Carmen, El concejo de Madrid en el tránsito de la Edad Media a la Edad Moderna, Madrid, Dykinson, 1999.

Luís López, Carmelo, Fuentes históricas de Guadalajara. Archivo Municipal de Guadalajara, III (1460-1473), Alcalá de Henares, Universidad de Alcalá de Henares, 2007.

Marcos Rodríguez, Florencio, Catálogo de documentos del Archivo Catedralicio de Salamanca (siglos XII al XV), Salamanca, Universidad Pontificia de Salamanca / CSIC, 1962. 
Martín Fuertes, José Antonio, «La Hermandad de 1448 entre los concejos de León, Zamora, Astorga y Toro», en Primer Congreso de Historia de Zamora, I. Fuentes documentales, Zamora, Diputación Provincial de Zamora, Instituto de Estudios Zamoranos, 1989: 337-350.

Martín Romera, María Ángeles, «Hermanas desiguales. Las jerarquías urbanas a través de las hermandades bajomedievales», Anuario de Estudios Medievales, 48/1 (Barcelona, 2018): 81-115.

Martínez Ruiz, Enrique, «Tradición y novedad en la organización político-administrativa de la Corona de Castilla en el reinado de los Reyes Católicos», Chronica Nova, 21 (Granada, 1993-94): 405-425.

Millares Carló, Agustín y Artiles Rodríguez, Jenaro, Libros de acuerdos del concejo madrileño, Madrid, Ayuntamiento de Madrid, 1932, vol. I.

Mínguez Fernández, José María, «Las hermandades generales de los concejos en la Corona de Castilla (objetivos, estructura interna y contradicciones en sus manifestaciones iniciales)», en Concejos y ciudades en la Edad Media hispánica. II Congreso de Estudios Medievales, Madrid, Fundación Sánchez-Albornoz, 1990: 537-568.

Mitre Fernández, Emilio, «Señorío y frontera (El Marquesado de Villena entre 1386 y 1402)», Murgetana, XXX (Murcia, 1969): 55-62.

Molina Molina, Ángel Luís, Colección de documentos para la Historia del Reino de Murcia, VII. Documentos de Pedro I, Murcia, Academia Alfonso X el Sabio, 1978.

Morales Muñiz, María Dolores, Alonso de Quintanilla. Un asturiano en la Corte de los Reyes Católicos, Madrid, Prensa y Ediciones Iberoaméricanas, 1993

Pascual Martínez, Lope, «Las hermandades en Murcia durante la Baja Edad Media (Un cuaderno de la Hermandad murciana, de 1478)», Miscelánea Medieval Murciana, III (Murcia, 1977): 161-210.

Pretel Marín, Aurelio, Una ciudad castellana en los siglos XIV y XV (Alcaraz, 13001475), Albacete, Instituto de Estudios Albacetenses, 1978.

Pretel Marín, Aurelio, «Convenios, hermandades y juntas medievales en La Mancha de Motearagón», Anales del Centro Asociado de la U.N.E.D. de Albacete, 1 (Albacete, 1979): 217-251.

Pretel Marín, Aurelio y Rodríguez Llopis, Miguel, El Señorío de Villena en el siglo XIV, Albacete, Instituto de Estudios Albacetenses, 1998.

Puñal Fernández, Tomás, El registro de la documentación notarial del concejo de la villa y tierra de Madrid, Madrid, Comunidad de Madrid, 2005.

Puyol y Alonso, Julio, Las hermandades de Castilla y León, Madrid, Imprenta de la sucesora de M. Minuesa de los Ríos, 1913. [Ed. facsímil, León, Nebrija, 1982].

Real Academia de la Historia, Cortes de los antiguos reinos de León y de Castilla, Madrid, Real Academia de la Historia, 1861-1903.

Rodríguez Molina, José, Colección documental del Archivo Municipal de Baeza (siglos XIII-XV), Jaén, Diputación Provincial de Jaén, 2002.

Ruiz de la Peña, Juan Ignacio, «La Hermandad leonesa de 1313», en León Medieval. Doce estudios, León, Colegio Universitario, 1978: 139-164.

Sánchez Benito, José María, Santa Hermandad Vieja de Toledo, Talavera y Ciudad Real (siglos XIII-XV), Toledo, Caja de Ahorro Provincial de Toledo, 1987. 
Sánchez Benito, José María, «La organización territorial de la Hermandad General (1476-1498)», Revista de Estudios de la Administración Local y Autonómica, 239 (Madrid, 1988): 1509-1528.

Sánchez Benito, José María, Colección de documentos de la Santa Hermandad Vieja de Toledo, Talavera y Ciudad Real (1300-1500), Toledo, IPIET, 1990.

Sánchez Benito, José María, «Observaciones sobre la Hermandad castellana en tiempos de Enrique IV y los Reyes Católicos», Espacio, tiempo y Forma, Historia Medieval, 15 (Madrid, 2002): 209-244.

Sánchez Benito, José María, «La Hermandad de los Montes de Toledo entre los siglos XIV y XV», Espacio, Tiempo y Forma, Serie III. Historia Medieval, 18 (Madrid, 2005): 209-230.

Sánchez Benito, José María, «Hermandades y delincuencia rural entre el Tajo y Sierra Morena (Siglos XIII-XV)», Clío e Crimen, 3 (Durango, 2006): 134-166.

Sánchez Benito, José María, «Hermandades concejiles en la frontera oriental de Castilla (Siglo XV)», en Mundos medievales. Espacios, sociedades y poder. Homenaje al profesor José Ángel García de Cortázar y Ruiz de Aguirre, Santander, Universidad de Cantabria, 2012a, vol. II: 1877-1888.

Sánchez Benito, José María, «Violencia y pugna política. Estudio de sus repercusiones en el mundo urbano a través del caso de Cuenca (siglo XV)», Studia Historica. Historia Medieval, 30 (Salamanca, 2012b): 237-262.

Sánchez Benito, José María, «Bandas armadas en los campos de la Corona de Castilla (siglos XIII-XV)», Vínculos de Historia, 5 (Ciudad Real, 2016): 54-71.

Sebastián Moreno, Javier, La ciudad medieval como capital regional. Burgos en el siglo XV, Madrid, Universidad Autónoma de Madrid, 2017.

Sebastián Moreno, Javier, «Las hermandades concejiles del siglo XV. Jerarquía, centralidad y roles de la ciudad de Burgos en la red de asentamientos de Castilla», en Élites, conflictos y discursos políticos en las ciudades bajomedievales de la Península Ibérica, Salamanca, Universidad de Salamanca, 2019: 53-76.

Serrano, Luciano, Los Reyes Católicos y la ciudad de Burgos, Madrid, CSIC, 1943.

Soler García, José María, «Aportación documental a la historia albacetense de los siglos XIV y XV», en Congreso de Historia de Albacete, II. Edad Media, Albacete, Instituto de Estudios Albacetenses, 1984: 223-238.

Suárez Fernández, Luis, «Evolución histórica de las hermandades castellanas», Cuadernos de Historia de España, XVI (Buenos Aires, 1951): 5-78.

Suárez Fernández, Luis, Historia del reinado de Juan I de Castilla, Madrid, Universidad Autónoma, 1977.

Torres Fontes, Juan, «La Hermandad del Marquesado de Villena de 1386», Villena, 23 (Villena, 1973): 32-39.

Urosa Sánchez, Jorge, Política, seguridad y orden público en la Castilla de los Reyes Católicos, Madrid, INAP, 1998.

Valdeón Baruque, Julio, Los conflictos sociales en el reino de Castilla en los siglos XIV y XV, Madrid, Siglo XXI, 1979.

Recibido: 31/05/2020

Aceptado: 10/04/2021

Hispania, 2021, vol. LXXXI, n. ${ }^{\circ} 268$, mayo-agosto, págs. 455-482, ISSN: 0018-2141, e-ISSN: 1988-8368

https://doi.org/10.3989/hispania.2021.013 